\title{
Los folletos, reflejo de una época (1893-1910)
}

Graziella Altamirano

Ma. Eugenia Arias

INSTITUTO MORA

Revisión de los diferentes temas tratados en los folletos publicados durante el periodo que comprende el auge y declive del porfiriato.

Sin scrvicios eficaces y expeditos que acumulen, ordenen y divulguen la información, no puede haber desarrollo de la investigatción.

Enrique Florescano

$\mathbf{P}$

ara cualquier interesado en asuntos del pasado, las guías y los catálogos de documentos, así como las compilaciones, bibliografias y antologías, resultan por demás útiles en sus investigaciones. Quienes hemos profundizado en el conocimiento histórico sabemos, por experien- cia, que el camino para llegar al objeto es arduo cuando los materiales se hallan dispersos, desordenados o simplemente son inaccesibles.

Por eso, todo esfuerzo abocado a prestar un servicio más ágil y eficaz en archivos y bibliotecas, cada aportación que los investigadores podamos brindar, ordenando y divulgando los materiales básicos de nuestros trabajos, es una labor fecunda. Permite a los estudiosos tener un mayor y mejor acceso a los acervos y, paralelamente, deja apreciar de manera más práctica y precisa la riqueza de la información e impulsa, sin duda, el conocimiento. 


\section{SECUENCIG}

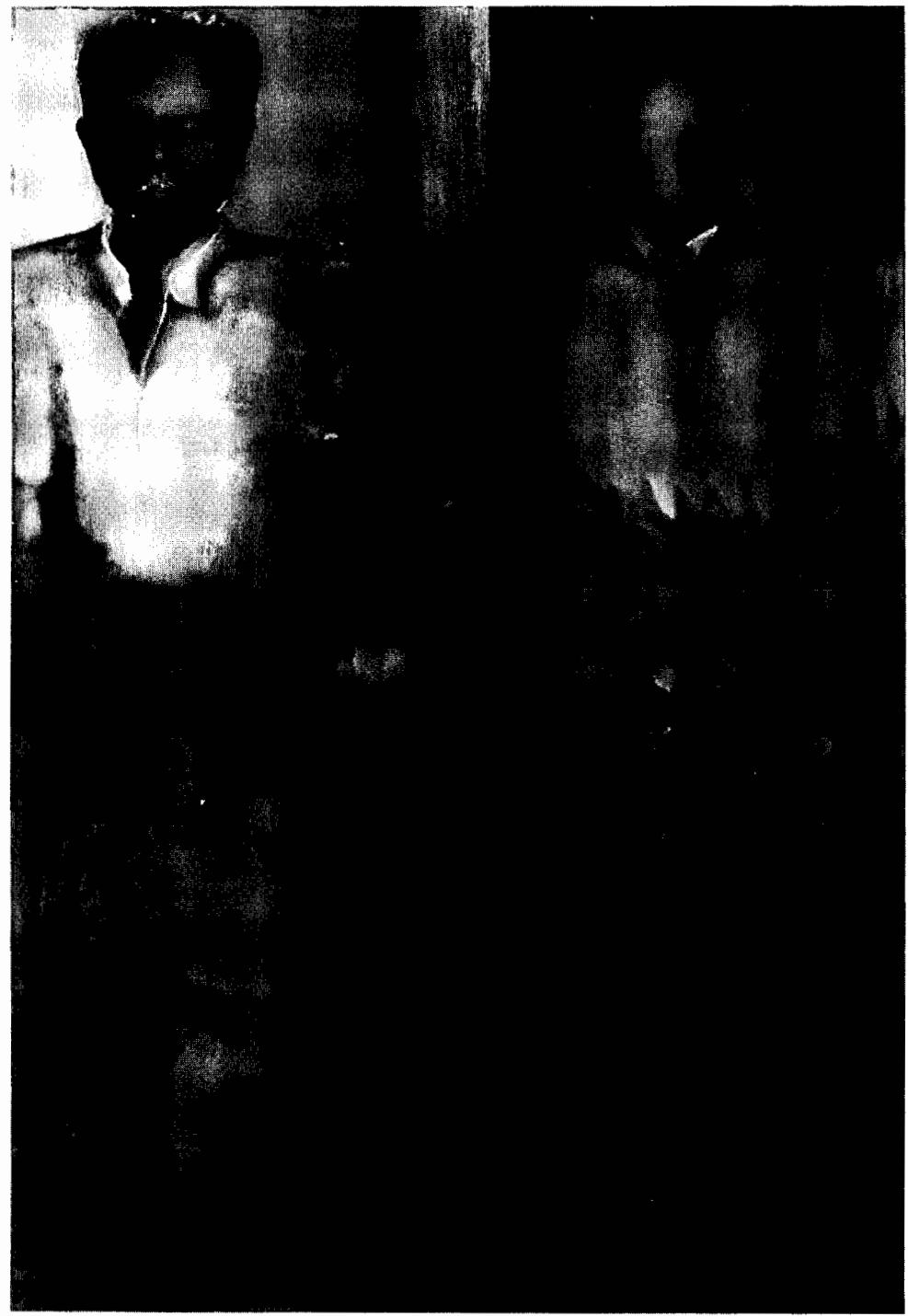

116

Ilustraciones de Adrián Bellón Pérez. Queda estrictamente prohibida la reproducción total o parcial de las imágenes publicadas en este número de la revista Secuencia, 39.

Las imágenes fueron contratadas y/o donadas de forma exclusiva para esta publicación. 
El proyecto de Folletería ha favorecido este tipo de apoyo, y hoy día ya reúne, en forma clasificada, un cúmulo de registros de folletos del siglo XIX y de la primera década del xx localizados en diversos acervos de nuestro país y de Estados Unidos, los cuales comprenden títulos alusivos a las diversas manifestaciones de la vida nacional en cada uno de los periodos demarcados, ordenados porfactores parafines prácticos de trabajo.

La revisión de poco más de 4200 títulos de folletos publicados entre 1893 y 1910 , y su clasificación por rubros, nos permitió, aun cuando no examinamos sus contenidos, tener una idea bastante clara de la folletería que predominó durante ese tiempo y del papel que desempeñó como espacio de expresión y canal de divulgación. Asimismo, nos reveló, de una manera nítida, el peso de ciertas temáticas correspondientes a determinados descriptores generales que, por su abundancia, nos dibujaron de alguna manera las líneas que definieron esa época.

El periodo comprendido entre 1893 y 1910 enmarca el auge y el declive del porfiriato. Su inicio se ubica, justamente, cuando se ha consolidado la paz como condición prioritaria para el desarrollo del país; cuando se ha logrado, como afirmara Porfirio Díaz al final de su mandato, una "paz forzosa, necesaria para que la nación tuviera tiempo de pensar y trabajar". La estabilidad y el orden abren las puertas al progreso económico y estas premisas se convierten en una necesidad vital durante todo el régimen. Es en la década de los noventa cuando se encauza abiertamen- te el fomento material, y la modernización de la economía ocupa un sitio privilegiado. México y la explotación de sus recursos atraen la confianza de inversionistas extranjeros que, con el fin de obtener altas ganancias, se interesan en diversos ramos que requieren no sólo de capitales abundantes, sino también de una tecnología avanzada.

Durante esos años, la economía se vigoriza por la demanda internacional de materias primas $y$, como consecuencia, se reactivan la agricultura, la ganadería, el comercio interior y la industria. Se advierten los síntomas de un consistente crecimiento económicoque ofreceoportunidades, sobre todo a los extranjeros, para la construcción cada vez más acelerada de vías de comunicación y de obras de infraestructura; para la formación de núcleos modernos como minas y fábricas, para el establecimiento de instituciones bancarias, y para la rehabilitación del campo.

Haciendo un balance cuantitativo de los folletos clasificados por rubros, la Obra económica arroja las cifras más elevadas. La folletería es reveladora de la economía de los últimos años del siglo, cuando México ha logrado estabilizar las finanzas públicas y cuenta con un crédito internacional que le permite dedicarse a la construcción de grandes obras de infraestructura, como ferrocarriles, caminos, telégrafos, teléfonos y puertos. Abundan los títulos que refiejan el vertiginoso crecimiento del sistema ferroviario; se publican, incluso en otros idiomas, contratos, informesy programas de compañías extranjeras; estudios sobre el régimen 
y la organización que impera en los ferrocarriles; leyes y reglamentos que dan cuenta del plan general de comunicaciones para la construcción y tendido de vías y las concesiones en este importante ramo que despiertan el interés de los extranjeros, los cuales, atraidos por una legislación favorable, buscan nuevos espacios para sus capitales. Se imprimen estatutos de creación de nuevas empresas, informes de accionistas, reseñas de inauguraciones, leyes que regulan el registro de contratos, y se editan tarifas de efectos, así como reglamentos para empleados.

En el rubro de Comunicaciones están presentes, aunque en mucha menor cuantía, los folletos que se ocupan de obras portuarias y líneas marítimas, así como del telégrafo, el correo y el teléfono, ramos que para los primeros años de la clécada de los noventa están bajo la jurisdicción de la Secretaría de Comunicaciones. El cableado telegráfico crece considerablemente, el servicio postal se vigoriza y el teléfono cuenta, hacia finales del siglo, con más de 5000 aparatos en el país. Destacan en este apartado los folletos que contienen directorios telefónicos y algunas tarifas, sobre todo postales, así como estudios sobre el derecho de correspondencia postal, telegráfica y telefónica.

Un gran renglón económico que pesa considerablemente en la folletería del periodo es el de Minas, bajo cuya temática se registran 123 títulos. México es rico en minerales y por ese tiempo se ha reactivado este ramo por una creciente demanda de materias primas. Ingleses y estadunidenses, aunque no dejan de tener un papel importante los capitales mexicanos, se interesan en explotar y beneficiar yacimientos minerales. Los folletos nos remiten a ensayos, proyectos e informes relativos a minas y compañías mineras, estudios tecnológicos de extracción y fundición, investigaciones sobre minerales y vetas de muchas partes del país, concesiones y contratos, compendios sobre unidades de peso para minerales y productos metalúrgicos, escrituras constitutivas y estatutos, asi como leyes y reglamentos mineros. Todo ello da una clara idea del extraordinario auge que alcanza el ramo minero en estos años con la creciente explotación de metales industriales, y aun de yacimientos petrolíferos, que intensifican la competencia extranjera.

Lo que se produce en el México urbano y rural constituye el principal resorte de la vida económica. El brillo del progreso traspasa las fronteras de nuestro país y diversos sectores exhiben al mundo un muestreo de su riqueza material. Los folletos dan cuenta de la presencia de México en exposiciones universales como la de San Luis Missouri, Buffalo, París e Inglaterra.

En el rubro de Fomento-obras de infraestructura se registran 65 títulos, en los que destacan los correspondientes a obras públicas - no sólo de la ciudad de México, sino de varias urbes clel país como Guadalajara, Durango, Chihuahua, Villahermosa y Tampico- relativos a drenaje, entubación y canalización de aguas, construcción cle presas y puentes, sistema de sane:miento, mejoras materiales y tranvías, contratos para pavimentar calles y establecer el sistema de alumbrado y agua potable. Sobresalen diversos estudios acerca de 
bombas y atarjeas, así como títulos referentes a los trabajos e inauguración del desagüe del valle de México que aminorarán el grave problema de las inundaciones. Todos estos trabajos de fomento van acordes con una época en que, en muchas partes del país, se lleva a cabo la expansión de nuevos servicios, en cuyas tareas participan compañías extranjeras, intermediarios $\mathrm{y}$ grupos locales que fundan nuevas sociedades para invertir en obras públicas y contratar con el gobierno.

Después de los ferrocarriles, de las minas y de los servicios, la banca constituye otro pilar de la economía para consolidar el progreso, y es uno de los espacios privilegiados de las inversiones extranjeras. Durante el periodo estudiado se expide una nueva ley de instituciones de crédito que autoriza el establecimiento de los bancos de emisión en todos los estados de la repúblicay se reglamenta el funcionamiento de los hipotecarios y refaccionarios; 51 folletos de esta época, referentes a bancos, contienen reglamentos interiores, estatutos y contratos de concesión, informes de consejos de administración, leyes y circulares sobre el sistema de crédito, ensayos en torno a la organización bancaria y, a partir de 1905 , acerca de la reforma monetaria, después de la cual se estrechan aún más los vínculos de la economía mexicana con el mercado internacional.

La creación de un sistema crediticio, las medidas proteccionistas y la exención de contribuciones favorecen los ramos industrial y mercantil. Junto a los establecimientos fabriles tradicionales se crean otros modernos en varias partes del país, donde están pre- sentes los empresarios nacionales y extranjeros; el comercio se vigoriza con el intercambio tanto de productos minerales, como textiles y agrícolas (algodón y azúcar). En la folletería de la época registramos 134 títulos sobre empresas y sociedades mercantiles que nos remiten a escrituras constitutivas de firmas comerciales, así como a estatutos e informes de nuevas compañías; paralelamente, observamos que los folletos son un medio de clivulgación de los sonados procesos judiciales en los que algunas negociaciones se vieron involucradas.

Con el fin de dinamizar el campo, se asientan las bases jurídicas que legitiman la propiedad agraria de aquellos dueños que invierten capitales en haciendas, ingenios y otras unidades productivas, que revitalizan mediante nueva tecnología. Si bien la legislación del periodo intenta desamortizar la tierra dando continuidad al proyecto liberal, encauza el latifundismo y se sostienen numerosos litigios por tierras y aguas entre comunidades y haciendas a causa del despojo. Los 114 folletos registrados en el renglón de Tierras y aguas proporcionan un material muy rico a quienes abundan en la historia agraria de nuestro país, y quizá permiten captar una prefiguración de las tensiones previas a la revolución.

Hacia finales del siglo, México obtiene de sus finanzas un excedente que logra mantener hasta el término del porfiriato. La Obra legislativa en el ámbito económico se intensifica, y los folletos son uno de los principales vehículos para difundirla. Son emitidos nuevos códigos de colonización, mi- 
nería, comercio, banca e inversión extranjera; se suprimen las alcabalas y se expiden leyes sobre tierras y aguas. El resurgimiento financiero proporciona al gobierno recursos fiscales crecientes, por lo que aumenta la presión en las contribuciones, tanto a nivel federal como estatal y municipal. Se estimulan las exportaciones por medio de la ampliación de concesiones para la explotación de materias primas y la modificación de los aranceles y leyes de impuestos, lo cual encontramos ampliamente documentado en el material revisado.

Por lo anteriormente señalado, puede explicarse el peso notable de la Obra jurídica dentro de la folletería del periodo, en la que distinguimos dos bloques principales: por un lado, el de los materiales que van de la mano con la política económica y, por otro, el de aquellos cuyos temas son de orden político y social. En el primer grupo abundan los alegatos, las exposiciones y las querellas en torno a las cuestiones materiales, los juicios sobre propiedad de tierras y otros bienes, los litigios por fincas y aprovisionamiento de aguas, los amparos de compañías mineras, los alegatos sobre hipotecas y los estudios sobre sentencias. Mientras que en el segundo hay títulos referentes a estatutos y reglamentos, amparos y fallos, ordenanzas, discursos, ensayos, leyes y decretos, así como puntos de derecho. Aquí destacan también las constituciones locales, los estudios concretos que las reforman, los informes sobre la función de jefes políticos y, en otro sentido aunque también en el segundo bloque, los materiales básicos que susten- tan la política educativa y algunos temas de interés social, como los que tratan de remediar el alto nivel delictivo de la época con las reformas de los sistemas penitenciarios y las modificaciones a los códigos de procedimientos penales, así como la discusión del controvertido tema del divorcio.

Paralelamente al crecimiento económico, la senda del progreso conduce también hacia un orden social basado en los principios de la ciencia, y ésta es el objeto del conocimiento que más se cultiva en el ámbito cultural de la época. Fomentadas por la paz porfiriana, proliferan las asociaciones científicas que, si bien cuentan con sus propios canales de divulgación, como revistas especializadas, gacetas, anuarios, memorias, etc. - no considerados dentro de nuestra tarea de recuperación-, utilizan profusamente los folletos como recurso complementario de difusión de la ciencia, los que por su abundancia nos dan una idea del importante papel que desempeñaron en esa época. La agricultura y la minería, como sectores primarios de la economía, así como la física, la química, la biología, la geografía, la geología y otras ciencias son impulsadas sistemáticamente gracias a los estudios referentes a técnicas y cuidados de cultivos, procedimientos de extracción y preparación de metales, descubrimientos en laboratorios, investigaciones de diversas especies vegetales y animales, notables exploraciones geológicas, etc., que contribuyen a los avances teóricos y prácticos en el quehacer científico.

La medicina ocupa un renglón especial. Sobresalen los impresos de la 
Escuela Nacional de Medicina y del Instituto Médico Nacional, que dan a conocer sus programas y actividades; se difunde la participación científica de nuestro país en congresos internacionales; son publicados los trabajos presentados en los famosos concursos científicos de la época y se dan a conocer nuevos métodos en la práctica médica. Los folletos asumen una función esencial en el ramo de Salud pública, pues informan acerca de la prevención de enfermedades, de los perjuicios que ocasiona el alcoholismo, así como los beneficios de la higiene y la vacunación durante los años difici. les de las epidemias de tifo y viruela. Por otra parte, abundan las tesis de médicos-cirujanos-parteros y las disertaciones de exámenes sobre temas farmacológicos que, si bien hemos tomado en cuenta porque corresponden al formato de los folletos, creemos que no tienen la misma función de divulgación que éstos.

En el apartado sobre Obra de tema social, el número de registros también es considerable, sobre todo por el peso que tienen los rubros relativos a asociaciones y a educación.

Sin lugar a dudas, el despegue económico del porfiriato acelera los cambios sociales. El progreso y el sistema de privilegios otorgados a una mínima parte de la población afecta estilos de vida y acentúa los contrastes entre las actividades modernas y las viejas formas de subsistencia. La modernización progresiva tiene como consecuencia el predominio de estructuras mutualistas y de nuevas organizaciones de tipo corporativo que, a la par del crecimiento de la industria, se incrementan en vísperas de la revolución. Son 155 los folletos que hacen referencia a asociaciones, de los cuales un buen número procede de las ciudades más importantes del país, dando cuenta de sociedades de artesanos y obreros, de alianzas y círculos de trabajadores que se crean para defender sus intereses, fundar cajas de ahorro y fomentar sus actividades recreativas. Sin embargo, no se detectan las protestas, huelgas y rebeliones de los últimos años del régimen generadas por las debilidades y contradicciones sociales existentes. Percibimos en los títulos registrados bajo esta temática que, si bien a través de la publicación de discursos y conferencias de estas sociedades podrían despertar de alguna manera los folletos la conciencia de los trabajadores, más bien su función gira en torno a la divulgación de sus formas organizativas de cooperación, siendo otros los canales de comunicación, comola prensa política, para hacer proselitismo y manifestar el descontento social.

En cuanto a la educación, clurante el periodo revisado se advierte un giro en la política hacia ese ramo. En esta época se crea la Dirección General de Instrucción Primaria para uniformar la enseñanza en todos los establecimientos; se reforman los métodos pedagógicos; la Escuela Nacional Preparatoria es objeto de una atención especial por parte del régimen, y las escuelas normales para profesores son el orgullo del sistema. En diversos estados de la república, los colegios aumentan el número de carreras y, a nivel municipal, se incrementan los recursos para el progreso de la enseñanza. Son expedidos numerosos títulos a maestros y 
médicos, así como a abogados, notarios, ingenieros de minas, topógrafos, farmacéuticos, etc. Alcanzan un número importante los folletos que contienen planes de estudio y los que se editan como cartillas de diferentes materias, así como manuales y nociones prácticas que sirven de apoyo a la enseñanza. Sin embargo, a pesar de los serios intentos de reformar la educación pública, lo cual queda asentado en el abundante material que registramos en el área de Organización (242 títulos), sólo se ve beneficiada una minoría de la sociedad. El campo y los pueblos tradicionales son desatendidos, y los indígenas son sólo considerados por su pasado arqueológico y prácticamente olvidados en sus necesidades materiales y culturales, lo cual arroja un elevado índice de analfabetismo en el país.

Una aportación importante en el ramo educativo lo constituye la Iglesia. Es significativa la presencia del clero en las instituciones de enseñanza para niños y jóvenes, tanto en las ciudades como en algunos pueblos y haciendas y, en este renglón de la folletería, destaca su presencia en los colegios particulares, en las escuelas parroquiales y en Ios múltiples seminarios que dirige a lo largo de la república, de los cuales se benefician muchos laicos.

Durante el régimen de Díaz, la política de conciliación tiene en la Iglesia el apoyo de una fuerza fundamental que se consolida durante el periodo que nos ocupa, cuando prácticamente pasan inadvertidas las Leyes de Reforma -en esta época ya incorporadas a la Constitución- y se observa una mayor tolerancia hacia las actividades religiosas públicas, siempre y cuando se colabore en bien del régimen. Es en esta época cuando la Iglesia recupera su presencia y aumentan las diócesis, las parroquias, los seminarios y el número de sacerdotes. Los folletos relativos a la Obra eclesiástica de estos años destacan en dos renglones principales: en primer término, las cartas pastorales, que suman 103, conteniendo las principales ideas doctrinarias dirigidas hacia la grey católica, así como la información de los puntos tratados en las encíclicas, en los concilios provinciales y en los congresos católicos y, en segundo lugar, todo lo relativo al culto mariano que, en 122 títulos, refleja el reconocimiento a la histórica devoción de los mexicanos, la cual alcanza su punto culminante con la brillante coronación de la Virgen de Guadalupe en 1895. En rangos menores destacan las publicaciones sobre historia de la Iglesia, las celebraciones religiosas, así como los edictos episcopales y los catecismos morales.

Porfirio Díaz es un mecenas de los historiadores de la etapa, y se propone crear una conciencia histórica que contribuya al fortalecimiento de México. El régimen impulsa el quehacer histórico favoreciendo la creación de una infraestructura: se mejoran el Archivo, el Museo y la Biblioteca nacionales, cuyos catálogos son publicados como folletos; se inaugura la Escuela Nacional de Altos Estudios y se promueve la publicación de obras monumentales de la historia de México y de revistas como Museo Nacional.

En la Obra histórica, el positivismo plantea llegar a la verdad positiva, a lo que se puede comprobar del pasado. 
Habremos de subrayar que la publicación de documentos es muy importante en el periodo, ya que revela el sentido de aquellos que, en el quehacer histórico, se proponen rescatar todo lo que permite verificar lo acontecido. Se reúne una alta cifra de títulos sobre historia de México; en éstos se incluyen estudios arqueológicos y ensayos sobre cultura antigua (algunos en inglés), descripción de códices y de los hechos correspondientes a la conquista; existen manuales útiles sobre geografia e historia en lengua náhuatl, recuentos históricos sobre la colonia, la etapa independentista y la Intervención francesa. Las biografias rescatan a los frailes y otros religiosos, a los próceres de la Independencia, a los liberales del XIX y a otras figuras como las de Agustín de Iturbide, BenitoJuárez, en el centenario de su natalicio y Porfirio Díaz. Por otro lado, hay textos de "nociones de historia patria" para las escuelas primarias, y aquellos que tratan temas de actualidad en ese entonces: México bajo el gobierno de Díaz (con títulos en francés). Las historias locales, los relatos históricos para niños, los tratados en que se hace crítica histórica, especialmente las polémicas sobre la Virgen de Guadalupe y sobre la obra de Francisco Bulnes relativa a Juárez, se hallan en importante cantidad. Uno que otro título sobre historia universal también se encuentra en la sección de Obra histórica.

Los folletos ubicados dentro de Obra sobre arte son escasos. Arrojan algunos estudios específicos sobre monumentos. Esto tiene una razón de ser: en el periodo hay una tendencia a nutrir el conocimiento arqueológico, y esto se logra gracias a las exploraciones de algunos científicos sociales de nuestro país y del extranjero, quienes se aventuran a descubrir los rasgos, así como los vestigios, del pasado antiguo y colonial. Las noticias de sus hallazgos en centros prehispánicos y en edificios civiles y religiosos de la época virreinal circulan a través de los folletos. Cabe mencionar que entre los materiales referentes a monumentos se da cuenta, asimismo, de las solemnes inauguraciones de estatuas y recintos dedicados a los próceres de la independencia, sobre todo, de aquellas en las que se dan cita don Porfirio y la "crema y nata" de la sociedad como parte de los eventos llevados a cabo para las fiestas del Centenario en 1910.

Gente dedicada al cultivo de la música, y estudios especializados en la arquitectura, la pintura y algunas artes menores, dan curso a sus apuntes y propuestas teóricas y técnicas, así como a sus breves ensayos, a través de la folletería. Algunos de estos materiales permiten conocer la incuietud de varios hombres cultos por rescatar la historia del arte, aunque en este campo notamos una diferencia importante si comparamos con el número de títulos que arroja el tema de Obra histórica en general. Una que otra referencia sobre exposiciones y museos se localizan también en lo que corresponde al tema de arte.

En los títulos clasificados dentro de la Obra literaria, los de Composiciones poéticas alcanzan un número significativo: 127 folletos. Son menos los que reflejan la producción de novelas, cuentos y relatos, así como las piezas de teatro que, a su vez, sobrepasan los 
elogios, los panegíricos y las coronas fúnebres. Estos tres últimos rubros exaltan a la Virgen, a los héroes de la independencia, a Juárez, sin faltar la figura de Díaz, algunos gobernadores y uno que otro obispo. Los discursos presentados en la inauguración de monumentos, veladas literarias y congresos aluden, en ocasiones, al protocolo oficial, y en otras, a la costumbre de individuos, que pertenecen a la elite culta, que se reúnen espontáneamente en intimas tertulias. Los vocabularios y gramáticas, los relatos de viajeros, la crítica literaria y los ensayos son pocos, comparados con todos los anteriores.

La obra referida a periódico es pobre. Los títulos sobre artículo periodístico suman 36 folletos, que rescatan noticias de temas variados y una que otra polémica.

La dictadura tiene un apoyo básico en el ejército, pero si hablamos de materiales escasos, la temática que se adecua a esta observación es la Obra militar. En el periodo que atendemos, los títulos relativos a ella son pocos, y sólo nos revelan la importancia de la reorganización en este sector, con base en ordenanzas y reglamentos, manuales técnicos y una legislación propia. Si bien en lo que se refiere a causas personales y sentencias, manifiestos y proclamas, y hojas de servicio, son rubros que podríamos haber esperado encontrar en mayor cuantía, nos sorprende su pobreza dentro de la folletería que revisamos, lo cual nos hace suponer que este tipo de materiales han de estar, por su carácter oficial, en los acervos del Archivo de la Defensa Nacional.
En principio podría pensarse que la folletería del periodo arrojase una cantidad considerable de títulos correspondientes a la Obra política. Para nuestra sorpresa, la cifra ocupa una media si hacemos un balance entre los folletos de mayores y menores unidades. Los materiales clasificados en ese tema nos recuerdan aquel sonado lema porfiriano de "poca política y mucha administración". Destacan en un número de 227 los discursos y ensayos políticos y, en menor cuantía, los informes y memorias oficiales, las noticias sobre celebraciones cívicas, donde sobresale la oratoria conmemorativa, los documentos relativos a una persona, las polémicas y la organización de la administración pública. Los folletos sobre elecciones y política exterior, así como las actas, los dictámenes y los papeles sobre representación parlamentaria son muchos menos y, un número muy pobre, los manifiestos y las proclamas, las circulares y los títulos sobre correspondencia y libertad de imprenta.

Durante el porfiriato, la Constitución de 1857 sufrió varias reformas que le otorgaron facultades extraordinarias a Díaz y que le permitieron afianzar la estructura del régimen. Siguiendo el modelo, los gobernadores de los estados hicieron cambios a las cartas locales para alcanzar los fines prácticos del gobierno y para asegurar su autoridad. Los ejecutivos del interior eran los pilares fundamentales de la dictadura, y sus puestos, generalmente vitalicios y preeminentes sobre los poderes legislativo y judicial. La folletería refleja la importancia del papel que jugaron los gobernadores y 
la condición necesaria de su reelección, perollaman sobremanera la atención, los títulos que anuncian, aluden, demuestran y, en suma, reflejan una época que ya vive su ocaso. La presencia de la oposición abre brecha en la folletería de la obra política de los últimos años.

A fines del siglo XIX, el gobierno de Porfirio Díaz era admirado por propios y extraños. México era visto como una nación culta, moderna, civilizada, gracias a los alcances obtènidos por la dictadura. Su gran capital, la ciudad de México, es un botón de muestra; sede del progreso y de un gobierno garante de la tranquilidad. La confianza depositada en el "pilar de la paz y del progreso", en el "prohombre" y gobernante "hacedor del México moderno" contrasta con la visión que condena al contralor de "mano de hierro" y al dador de "pan y palo". Pero en el primer decenio del $\mathrm{xx}$ hay síntomas claros de la decadencia del régimen. La atmósfera de descontento, creada por la injusticia, la desigualdad y la pobreza se revela de diferentes maneras; se manifiesta como crítica y luego, como abierta oposición a la dictadura.

Es a partir de los primeros años de nuestra centuria que se empiezan a canalizar las protestas procedentes de diversos sectores de la población que esperan un cambio en el país. Dirigentes y representantes del grupo opositor, ya como teóricos, ya como críticos, manejan la pluma para propagar sus ideas, y es en la folletería del periodo que observamos un buen número de materiales cuya riqueza es, a nuestros ojos, más cualitativa que cuantitativa. Titulos como Nueva Democracia,
El problema actual: la vice-presidencia de la república, y Cuestiones electorales, nos ilustran sobre aquella fase postrera de la época porfiriana, justo cuando la oposición se evidencia abiertamente.

La avanzada edad de Díaz gencra en las altas esferas del gobierno una inquietud que se muestra cada vez más franca. ¿Quién habría de quedar a la cabeza del régimen en caso de su retiro o muerte? La entrevista DíazCreelman de 1908 abre la contienda electoral, tanto para quienes aspiran al cambio, como para los que anhelan una continuidad. El tema de quién quedará en el ejecutivo es por demás recurrente y, para los primeros, la democracia es un asunto sobre el cual hay que escribir asiduamente y que hoy ha quedado dentro de la folletería. Las fiestas del Centenario en 1910 contrastan con la efervescencia de la oposición que se prepara a tomar las armas respondiendo al llamado de Madero.

Finalmente, podemos considerar que los folletos no sólo sugieren los rasgos de aquella época porfiriana a través de sus títulos; también revelan qué autores y lugares fueron los más generosos en la producción de este tipo de materiales, así como quiénes eran los editores más afamaclos de entonces, cuando no correspondió a diversas instituciones gubernamentales cumplir con la tarea de dejar una constancia documental del ejercicio material y cultural de aquella generación, que pocas veces disfrutó del régimen encabezado por Porfirio Díaz y muchas sufrió por las diferencias que éste impuso. 


\section{SECUENCIA}

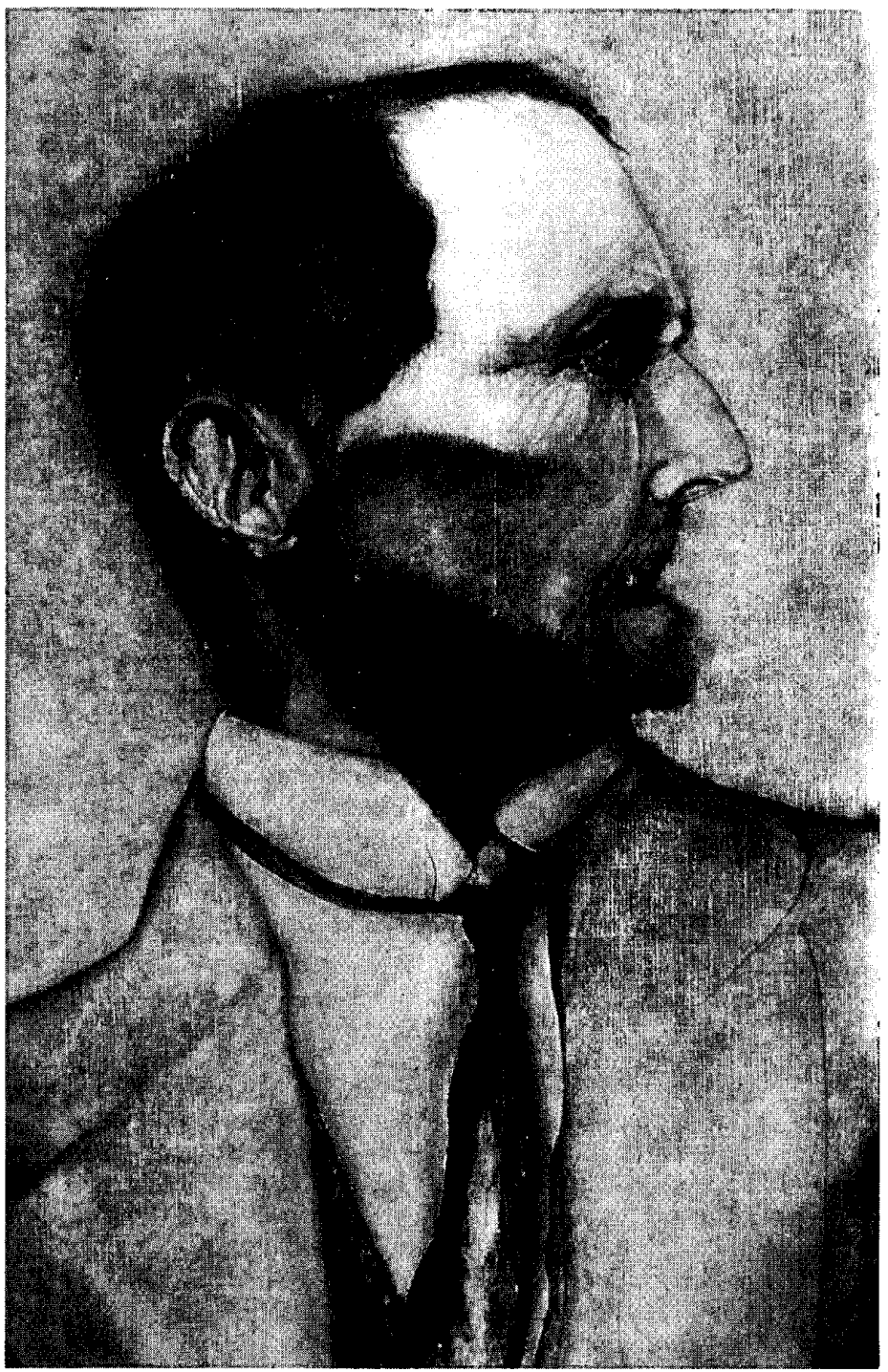

